\title{
Effects of Developed Electronic Instructional Medium on Students' Achievement in Biology
}

\author{
Nsofor Caroline Chinna ${ }^{1} \&$ Momoh Gabriel Dada ${ }^{2}$ \\ ${ }^{1}$ Department of Science Education, Federal University of Technology, Minna, Nigeria \\ ${ }^{2}$ Department of Industrial and Technology Education, Federal University of Technology, Minna, Nigeria \\ Correspondence: Nsofor Caroline Chinna, Department of Science Education, Federal University of Technology, \\ Minna, Nigeria. Tel: 234-803-678-3024. E-mail: geoama76@gmail.com
}

Received: January 21, 2013

Accepted: February 17, 2013

Online Published: April 2, 2013

doi:10.5539/jel.v2n2p1

URL: http://dx.doi.org/10.5539/jel.v2n2p1

\begin{abstract}
Abstact
The study investigated the effects of developed electronic instructional medium (video DVD instructional package) on students' achievement in Biology. It was guided by two research questions and two hypotheses, using a quasi-experimental, pretest-postest control group design. The sample comprised of 180 senior secondary, year two students from six schools located in the three education zones of Niger State. The subjects were divided into an experimental group (electronic medium instruction) and a control group (traditional lecture instruction). Structured Biology Achievement Test (SBAT) with internal consistency reliability co-efficient of 0.83 was used to measure the student's achievement before and after the treatment. The data obtained from the study were analyzed using Analysis of Covariance (ANCOVA). Results from Means, Analysis of Covariance (ANCOVA) and Scheffe test indicated that the achievement of students in biology greatly improved with the use of electronic instructional medium. Students' gender had no significant effect on their achievement in biology when electronic medium was used. These results have implications for innovative use of instructional media and creating sound strategies for disseminating science in the classroom.
\end{abstract}

Keywords: effects, electronic instructional medium, students' achievement, biology, Niger State

\section{Introduction}

Science and Technology have always been recognized as critical factors in the process of development. Through its application, the resources of nation have been transformed into goods and services all over the world. To support this, Abdulkadir (2011) remarked that the current development in science and technology have so greatly affected the live of every human being that to be ignorant of the basic knowledge of these developments is to live an empty, meaningless and probably unrealistic life. Consequently, Nsofor (2001) stressed that for any nation to attain the status of self reliance, science must be an important component of the knowledge to be given to all citizens of that nation irrespective of race, creed, or sex.

Biology which is an integral part of natural science is needed for our nation's technological breakthrough. According to Nsofor (2010), biology covers a wide scope, serves as a spring board for many future careers in science and technology and has application in nearly every field of life. For a nation to develop a social basis for modern technology, the study of biology which is now the brain behind the social growth is important since it forms veritable amour against misconceptions and superstition which muddles technological advancement anywhere.

Biology education has faced a lot of challenges over the years. Studies have shown a high enrolment and low achievement of students in internal and external biology examination (Olagunju, 2000; Kareem, 2003; Ezekannaya and Ikeagu, 2004). Ibe (2004) noted that these observed deterioration in students' achievement in biology must have been contributed by the strategies of teaching biology. Usman (2010) emphasized that the present mode of teaching biology in secondary schools whereby teachers' adopt only the lecture method does not in any way provide for sequence of learning experiences. There is therefore the need to explore other teaching approaches that will enhance and facilitate understanding and acquisition of the knowledge of what is being taught, hence the study, on Video DVD packages. 
Video DVD packages are instructional tools that posses the capacity to enhance quality learning, seek to arouse interests, stimulates thinking and concretize knowledge that could otherwise only be talked about in abstract terms. Agommuoh and Nzewi (2003) reported that video tapes have the potentials of increasing the probability that students will learn more, retain better and even improve their performance of the skills they are expected to develop. As important as this instructional medium is, it has been widely reported by researchers that both their teacher made version and foreign types are not readily available (Adelakun, 2003; Gana, 2000). It is therefore necessary to develop instructional video DVD package as an innovative approach in the teaching/learning of biology in secondary schools.

The influence of students' gender in their academic achievement had been a concern to researchers in education, yet no consistent result had emerged. Awoniyi (2000) and Balogun (2000) reported that gender had no significant influence on academic achievement of students while Mohammed (2000) and Mohammed (2004) reported that gender difference has influence on the academic achievement. Thus, the issue is still far from being conclusive. This shows that more work on gender differences and academic achievement is still needed. Gender is a variable in this study. The purpose of the study is to investigate the effects of developed electronic instructional medium (Video DVD instructional package) on students achievement in biology.

\section{Research Questions}

The following research questions guided the study:

1. What is the effect of developed video DVD instructional package and lecture method on students' achievement in biology?

2. What is the effect of developed Video DVD instructional package on gender in biology?

\section{Hypotheses}

1) There is no significant difference in the mean achievement of students taught with developed Video DVD instructional package and those taught with lecture method.

2) There is no significant difference in the mean achievement of students taught with developed video DVD instructional package and those taught with lecture method irrespective of gender.

\section{Materials and Method}

The study adopted a quasi- experimental, pretest-posttest control group design. Subjects in the two groups were pretested before the treatment to determine the equivalence of the two groups and after the treatment they were post tested.

\subsection{Sample}

One hundred and eighty (180) year 11 Senior Secondary School boys and girls were randomly sampled from six (6) co-educational schools located within three educational zones in Niger State. The design of the study is quasi-experimental; it involved a pretest, posttest control group.

\subsection{Research Instruments}

Research instruments were the developed Video DVD instructional package (VDIP), lesson plan and Structured Biology Achievement Test (SBAT). The Video DVD instructional package (VDIP) was developed by researcher based on the concepts taught to the students in the study, namely biology concepts of blood circulation and excretion as contained in the Senior Secondary II (SSII) biology core curriculum. An expert in the video recording did the recording and editing while the researcher did the narration. The VDIP was developed using script written information on series of lessons using models identifying scenes in the components of circulatory and excretory systems - the heart, blood vessels, procedure in the blood flow through the circulatory system, excretory system, components of nephron and mechanism of excretion. VDIP contains the video recordings of the models to suit narration on the concepts as detailed in the script write up. This was examined by specialists and comments and suggestions made by them were used in the production of the final VDIP. The necessity for researcher- made VDIP was based on the fact that the commercially produced DVD instructional packages are not common in Nigeria. Where they are available, they may not be directly relevant to the topic or objectives to be achieved in a lesson. As a result of this, developing a VDIP for use by the researcher was inevitable. The lesson notes on blood circulation and excretion were prepared by the researchers. This consisted of three sub-topics, proposed duration of the lesson, specific objectives, and steps for presentation and evaluation of the lesson. This, in turn was validated. 


\subsection{Test Instrument}

The test instrument used in collecting data for this study was researcher-developed structured Biology Achievement Test (SBAT). SBAT was a 40-item multiple-choice objective test with five options (A-E) drawn from SS11 biology curriculum on concepts of (1) Circulation and, Excretion in man. The test items covered different levels of understanding based on Bloom's taxonomy of educational objectives (i.e., Knowledge of facts, application of knowledge, interpretation of concepts). The content validity order of materials in the test was validated by experts in biology and educational measurement and evaluation. The reliability of the test instrument was determined by the pilot test method. Reliability index of 0.83 was established for the SBAT using the Pearson Product Moment Reliability Coefficient formulae.

\subsection{Data Collection Procedure}

The researcher visited the selected schools before the study started to determine the sample size and train the teachers that acted as research assistant. The SS11 biology teachers in the selected schools were trained as research assistants in the teaching of the biology concepts of circulation and excretion conventionally and with the package. Training was done in the selected according to the strategies assigned to each school. When the teachers had been adequately trained and demonstrated competence required of them, the sampling techniques procedure were followed. In each of the three educational zones, twenty (20) SS II students from three schools randomly selected were used. Three of the schools which served as an experimental group were taught by the use of Video DVD instructional package. This approach allowed students to stop, fast forward and rewind the disc as often as needed under the control of the biology teacher. The other three schools (control group) were taught by the conventional lecture method. The lessons for the experimental group were based on the same subject as that of control group with the presence of the teacher teaching in control group as the major difference. The treatment lasted for four weeks in all the six schools. Before treatment, the students were given a pretest to obtain a base for measuring learning gains of the instruction. At the end of the learning programme, SBAT was administered as post test.

\subsection{Data Analysis}

The research questions were answered by computing the mean achievement scores and standard deviations of the experimental and control groups while hypotheses were tested at $\mathrm{P}<0.05$ probability level using the Analysis of Covariance (ANCOVA) and Scheffe' test.

\section{Results}

The results in respect of mean and standard deviation of the students' achievement are in tables I and 2

Table 1. Means and standard deviations of the posttest mean achievement scores of experimental group and the control group

\begin{tabular}{llll}
\hline Variable & No in sample $(\mathrm{N})$ & Mean $(\mu)$ & SD \\
\hline Experimental group & 90 & 43.58 & 8.30 \\
Control group & 90 & 32.57 & 5.34 \\
\hline
\end{tabular}

Table 2. Means and standard deviations of the posttest mean achievement scores of experimental group and the control group irrespective of gender

\begin{tabular}{llll}
\hline Variable & No in sample $(\mathrm{N})$ & Mean $(\mu)$ & SD \\
\hline Experimental Group 2 male & 45 & 46.80 & 6.84 \\
Experimental group 2 female & 45 & 40.36 & 8.44 \\
Control group male & 45 & 32.82 & 5.50 \\
Control group female & 45 & 38.07 & 5.22 \\
\hline
\end{tabular}

The results in tables 1 clearly showed that the mean achievement scores of students in the experimental group were higher than that of students in the control group. Table 2 showed that male and female students in the experimental group had higher mean achievement scores than their male and female counterparts in the control group. The results of testing the two null hypotheses of the study by subjecting students mean scores to Analysis of Covariance (ANOVA) are shown in tables 3 and 4. 
Table 3. Analysis of covariance of the posttest mean achievement scores of experimental group and the control group using the pretest as covariant

\begin{tabular}{lllllll}
\hline Source & Dependent variable & Type III Sum of Squares & Df & Mean Square & F & Sig. \\
\hline Corrected Model & Postexp 1 & $408.379 \mathrm{a}$ & 2 & 204.189 & 2.465 & .091 \\
& Postcont & $59.733 \mathrm{~b}$ & 2 & 29.866 & 1.047 & .355 \\
Intercept & Postexp 1 & 5811.937 & 1 & 5811.937 & 70.162 & .000 \\
& Postcont & 2411.964 & 1 & 2411.964 & 84.533 & .000 \\
Precont & Postexp 1 & 401.567 & 1 & 401.567 & 4.848 & .030 \\
& Postcont & 51.686 & 1 & 51.686 & 1.811 & .182 \\
Preexp 1 & Postexp 1 & 4.503 & 1 & 4.503 & .054 & .816 \\
& Postcont & 9.064 & 1 & 9.064 & .318 & .574 \\
Error & Postexp 1 & 7206.744 & 87 & 82.836 & & \\
\multirow{2}{*}{ Total } & Postcont & 2482.367 & 87 & 28.533 & & \\
& Postexp 1 & 172053.000 & 90 & & & \\
Corrected Total & Postcont & 97995.000 & 90 & & & \\
& Postcont & 7615.122 & 89 & & & \\
\hline
\end{tabular}
a. $\quad$ R Square $=.054$ (Adjusted R Squared $=.032)$
b. $\quad$ R Square $=.023$ (Adjusted R Squared $=.001)$

An Examination of Table 3 revealed there is significant different between the posttest experimental group and the posttest control group. F $(70.16,84.533 ;$ df $1,89 \mathrm{p}<0.05$. The result revealed that the developed electronic medium produced a significant effect on the covariate effect (pretest) was controlled. The result indicatd that the treatment using electronic instructional medium accounted for the difference in the posttest achievement scores of the students. This implies that there is a significant difference in the interception among the groups, thus hypothesis one is rejected.

Table 4. Analysis of covariance of posttest mean achievement scores of male and female experiment group and male and female control group

\begin{tabular}{lllllll}
\hline Source & $\begin{array}{l}\text { Dependent } \\
\text { variable }\end{array}$ & $\begin{array}{l}\text { Type III Sum } \\
\text { of Squares }\end{array}$ & Df & Mean Square & F & Sig. \\
\hline Corrected Model & Mpostexp 1 & $357.780 \mathrm{a}$ & 2 & 178.890 & 1.936 & .157 \\
& Fpostexp 1 & $200.185 \mathrm{~b}$ & 2 & 100.093 & 1.395 & .259 \\
& Mpostcont & $25.564 \mathrm{c}$ & 2 & 12.782 & .410 & .666 \\
\multirow{3}{*}{ Intercept } & Fpostcont & $22.138 \mathrm{~d}$ & 2 & 11.069 & .394 & .677 \\
& Mpostexp 1 & 3873.356 & 1 & 3873.356 & 41.917 & .000 \\
& Fpostexp 1 & 2158.084 & 1 & 2158.084 & 30.078 & .000 \\
& Mpostcont & 1479.166 & 1 & 1479.166 & 47.459 & .000 \\
Precont & Fpostcont & 1365.271 & 1 & 1365.271 & 48.615 & .000 \\
& Mpostexp 1 & 243.128 & 1 & 243.128 & 2.631 & .112 \\
& Fpostexp 1 & 100.115 & 1 & 100.115 & 1.395 & .244 \\
Preexp 1 & Mpostcont & 25.509 & 1 & 25.509 & .818 & .371 \\
\hline & Fpostcont & 21.600 & 1 & 21.600 & .769 & .385 \\
\hline
\end{tabular}




\begin{tabular}{|c|c|c|c|c|c|c|}
\hline & Fpostexp 1 & 124.842 & 1 & 124.842 & 1.740 & .194 \\
\hline & Mpostcont & .158 & 1 & .158 & .005 & .944 \\
\hline & Fpostcont & 1.709 & 1 & 1.709 & .061 & .806 \\
\hline \multirow[t]{4}{*}{ Error } & Mpostexp 1 & 3881.020 & 42 & 92.405 & & \\
\hline & Fpostexp 1 & 3013.459 & 42 & 71.749 & & \\
\hline & Mpostcont & 1309.014 & 42 & 31.167 & & \\
\hline & Fpostcont & 1179.506 & 42 & 28.083 & & \\
\hline \multirow[t]{4}{*}{ Total } & Mpostexp 1 & 81367.000 & 45 & & & \\
\hline & Fpostexp 1 & 90686.000 & 45 & & & \\
\hline & Mpostcont & 49813.000 & 45 & & & \\
\hline & Fpostcont & 48182.000 & 45 & & & \\
\hline \multirow[t]{4}{*}{ Corrected Total } & Mpostexp 1 & 4238.800 & 44 & & & \\
\hline & Fpostexp 1 & 3213.644 & 44 & & & \\
\hline & Mpostcont & 1334.578 & 44 & & & \\
\hline & Fpostcont & 1201.644 & 44 & & & \\
\hline
\end{tabular}

a. $\quad$ R Square $=.084($ Adjusted R Squared $=.041)$

b. $\quad$ R Square $=.062($ Adjusted R Squared $=.018)$

c. $\quad$ R Square $=.019$ (Adjusted R Squared $=-028$ )

d. $\quad$ R Square $=.018$ (Adjusted R Squared $=-028)$

An examination of table 4 showed that significant difference existed among the groups as well as between the groups. $\mathrm{F}=41.917,30.078,47.459,48.615$, df $1,44 \mathrm{p}<0.05$

This shows that there is a significant difference in the interceptions among the groups. Therefore hypothesis two is rejected.

A follow up Scheffe' s post hoc multiple comparison test was conducted to locate the direction of the significant differences among the mean achievement scores of the experimental group male and female and control group male and female. The result is presented in Table 5.

Table 5. Summary of the Scheffe's post hoc multiple comparisons of the posttest mean achievement scores of experimental group and the control group irrespective of gender

\begin{tabular}{lllll}
\hline Variable (i) & Variable (j) & Mean diff. & Sign level & Remarks \\
\hline Male Expt 2 & Female Expt 2 & 6.44 & 0.0001 & Sig. \\
Male Expt 2 & Male control group & 13.98 & 0.0001 & Sig. \\
Male Expt 2 & Female control Group & 14.49 & 0.0001 & Sig. \\
Female Expt 2 & Male control Group & 7.53 & 0.0001 & Sig. \\
Female Expt 2 & Female control Group & 8.04 & 0.0001 & Sig. \\
Male control Group & Female control Group & 0.51 & 0.987 & Ns \\
\hline
\end{tabular}

Note. mean scores of variable (i) minus mean scores of variable (j) equals to the mean diff.

Table 5 indicates that there is significant difference in the post-test mean achievement scores of male in the experimental group 2 (Expt 2) that were taught with video DVD instructional package and both male and female control groups in favour of male Expt 2. In the same vein, there is significant difference in the mean achievement scores of female Expt 2 and both male and female control groups in favour of female Expt 2. 


\section{Discussion}

The mean achievement score of students in the experimental group was higher than that of the control group. Students taught with video DVD instructional package performed significantly better than those taught with the conventional method. The result also indicated that there is significant difference among male and female experimental group and male and female control group as well as between them. From this result, it could be inferred that video DVD instructional package has an enhancing effect on the teaching and learning of biology concepts irrespective of gender than lecture method. The significant difference may be as a result of the ability of the video DVD instructional packages to provide more concrete learning through a playback mechanism. It could be played, rewound, fast-forwarded and replayed by the learner for discussions and questions on difficult concepts. Also where audiovisual medium like video DVD package is used, learning environment is highly stimulating and the students motivated to take a greater interest in learning. This applies to students of all sexes and accounts for why male and female experimental group 2 students achieved significantly higher than their counterparts in the control group. The significant difference supports the fact that learning through audiovisuals such as video DVD used in this study is a vital key to assimilation of knowledge. When instructions are heard and visualized, they seek to arouse interest, clarify concepts, modify attitude and possess the capacity to enhance quality learning. Finally the knowledge is easily registered in the individual memory bank.

The above result is in agreement with previous findings of Ayagu (2000) and Nneji (2000), and Amamize (2001). They found that the use of video package in teaching and learning makes learning interesting and motivating to students. They clarified that video instruction serves as a spring board for further learning and that the flexibility of video package makes it an effective learning tool.

In the case of gender, the result is in agreement with the previous research findings of Awoniyi (2000), and Mohammed (2004). They came out with the finding that the use of electronic media enhanced both the performance of male students' more than females.

\section{Conclusion}

Students taught with the video DVD instructional package achieved better than students taught with the conventional /traditional method. Achievement was greatly improved irrespective of gender by the use of video DVD instructional package in teaching biology showing that the use of video DVD instructional package is independent of gender.

\subsection{Limitations of the Study}

The study is limited by the fact that Video DVD Instructional Package, is locally produced thus its quality might not be equated to the commercially made or imported types. Secondly teachers' variable is there, many teachers who were trained but for a short period were used, this might have affect on their capabilities, approaches to teaching and interaction with the students.

\subsection{Recommendations}

1) Secondary school biology teachers should effectively make use of video tapes/DVD in teaching the students irrespective of gender.

2) A Library of video packages in biology and other subject areas should be produced or purchased and kept in schools so that both teachers and students can borrow them for use as and when needed to do their work.

3) Qualified teachers who are already in the field and are not knowledgeable in the act of production and use of various instructional media should be re-trained through seminars, workshops, conferences and in-service programmes. The teachers who are still on training in various teacher training institutions should be exposed to educational technology courses to equip them with skills needed to face the challenges of inadequate or lack of instructional media prevalent in Nigerian schools.

\section{References}

Abudulkadir, A. A. (2011). Youths' Interest in Business and Technical Skill Acquisition. Its Implication for National Development. Journal of Science Technology and Mathematics Education, 7(3), 238-244.

Adelakun, S. A. (2003). Issues in Science Education for the Visually Impaired. In W. O. Fatokun, O. A., Adebimpe, O. K. Omoniyi, \& T. Ajoblene (Eds), Science and Technology in Special Education. Oyo: Tobistic Printing and Publishing Ventures.

Agommuoh, P. C., \& Nzewi, U. M. (2003). Effects of Videotape Instruction on Secondary School students Achievement in Physics. Journal of STAN, 38(1\&2), 88-93. 
Amamize, B. N. (2001). Nigeria Education Review. Journal of the School of Education, Adeniran Ogunsanya College of Education, 6(1), 197-199.

Awoniyi, A. S. (2000). Sex difference in an academic performance. Nigeria Journal of Gender and Development, l(82), 18.

Ayogu, Z. U. (2000). Enriching Science, Technology and Mathematics Education: The Role of New Media. Journal of Science Teachers Association of Nigeria, 10(5), 18-20.

Ezekannaya, G. N., \& Ikeagu, C. N. (2004). Constraints on STM Research Effectiveness in Nigeria.Proceedings of the $45^{\text {th }}$ Annual Conference Of STAN.

Gana, E. N. (2006). The use of instructional videotape in the learning of some geographical concepts (Map Reading) in Senior Secondary Schools in Minna. Unpublished M. Tech Education Thesis, Federal University of Technoligy, Minna.

Ibe, E. (2004). Effects of Guided- Inquiry and Demonstration on Science Process Skills Acquisition among Biology Secondary school Students. Unpublished M. ED. Thesis University of Nigeria, Nsukka.

Kareem, L. O. (2003). Effects of audio - graphic self instructional packages on Senior secondary school students' performance in biology in Ilorin, Nigeria. Unpublished Ph.D Thesis, Faculty of Educatin, University of Ilorin, Ilorin.

Mohammed, H. A. (2004). Development and Use of an Improvised Radio for Teaching and Learning of Physical Education in Primary School in Minna, Niger State. Unpublished M.Tech. Thesis, Federal University of Technology, Minna.

Mohammed, S. A. (2000). Assessment of Female Students' performance in selected Science courses. A case study of Federal Polytechnics Bida. Nigeria Journal of Gender and Development, 1(1\&2), 61-64.

Nneji, L. (2000). Videos film as a Science tool. Junior Integrated Science panel, 1(19), 134-145.

Nsofo, C. C. (2010). Effects of Improvised Instructional Media on Secondary School Students' Achievement in Biology Concepts in Niger State. An Unpublished Ph.D Thesis, Department of Science Education, Federal University of Technology, Minna.

Nsofor, C. C. (2001). Cultural Impediments on Women in Science, Technology and Mathematics Education. $42^{\text {nd }}$ Annual Conference Proceeding of STAN Ilorin.

Olagunju, A. M. (2000). An Investigation into Teachers attitude towards and extent of improvisation of resources for effective teaching of biology. $41^{\text {st }}$ Annual conference. Proceedings of STAN.

Usman, I. A. (2010). Investigation into the Effects of Discovery Methods of instruction On the Academic Achievement in Genetics among colleges of Education in North Western Nigeria. Journal of Science Technology and Mathematics Education, 7(1), 120-126. 